\title{
Association between payer status and patient-reported outcomes in adult patients with lumbar spinal stenosis treated with decompression surgery
}

\author{
Galal Elsayed, MD, ${ }^{1}$ Samuel G. McClugage III, MD, ${ }^{1}$ Matthew S. Erwood, MD,1 \\ Matthew C. Davis, MD, MPH, ${ }^{1}$ Esther B. Dupépé, MD, ${ }^{1}$ Paul Szerlip, PhD, ${ }^{2}$ \\ Beverly C. Walters, MD, MSc, FRCSC, ${ }^{1}$ and Mark N. Hadley, MD'1 \\ ${ }^{1}$ Department of Neurosurgery, University of Alabama at Birmingham, Alabama; and 'Department of Computer Science, University \\ of Central Florida, Orlando, Florida
}

\begin{abstract}
OBJECTIVE Insurance disparities can have relevant effects on outcomes after elective lumbar spinal surgery. The aim of this study was to evaluate the association between private/public payer status and patient-reported outcomes in adult patients who underwent decompression surgery for lumbar spinal stenosis.
\end{abstract}

METHODS A sample of 100 patients who underwent surgery for lumbar spinal stenosis from 2012 to 2014 was evaluated as part of the prospectively collected Quality Outcomes Database at a single institution. Outcome measures were evaluated at 3 months and 12 months, analyzed in regard to payer status (private insurance vs Medicare/Veterans Affairs insurance), and adjusted for potential confounders.

RESULTS At baseline, patients had similar visual analog scale back and leg pain, Oswestry Disability Index, and EQ$5 \mathrm{D}$ scores. At 3 months postintervention, patients with government-funded insurance reported significantly worse quality of life (mean difference 0.11, $p<0.001$ ) and more leg pain (mean difference 1.26, $p=0.05$ ). At 12 months, patients with government-funded insurance reported significantly worse quality of life (mean difference $0.14, p<0.001$ ). There were no significant differences at 3 months or 12 months between groups for back pain $(p=0.14$ and 0.43$)$ or disability $(p=0.19$ and 0.15$)$. Across time points, patients in both groups showed improvement at 3 months and 12 months in all 4 functional outcomes compared with baseline $(p<0.001)$.

CONCLUSIONS Both private and public insurance patients had significant improvement after elective lumbar spinal surgery. Patients with public insurance had slightly less improvement in quality of life after surgery than those with private insurance but still benefited greatly from surgical intervention, particularly with respect to functional status.

https://thejns.org/doi/abs/10.3171/2018.7.SPINE18294

KEYWORDS surgical outcomes; insurance disparities; lumbar spinal stenosis; lumbar surgery; lumbar decompression; Quality Outcomes Database

$\mathrm{L}$ UMBAR spinal stenosis is a frequent cause of lowback pain in the US population, affecting approximately $25 \%$ of the adult population per year. ${ }^{18}$ The number of surgical procedures performed for lumbar stenosis has shown a significant increase in recent years. ${ }^{7,10}$ With the advent of recent healthcare reforms and the implementation of plans such as the Affordable Care Act, patient-reported outcomes (PROs) have become increasingly important in the determination of quality of care and may be tied to reimbursement in the near future. ${ }^{8}$ Because of this, research studies that increase our understanding of disorders by evaluating the effects of varying factors on PROs are increasingly important.

Several studies have analyzed factors affecting PROs after lumbar spinal surgery. ${ }^{2,8,14,15,17}$ Similarly, some studies have evaluated PROs after lumbar spinal surgery, comparing private insurance with either a general public insurance cohort (Medicare, Medicaid, and Veterans Affairs [VA]) or Medicaid insurance alone..$^{14,15,18}$ None, however, have focused specifically on the relationship between private insurance versus government non-Medicaid insurance (i.e., Medicare or VA insurance) and PROs after lumbar spinal

ABBREVIATIONS ASA = American Society of Anesthesiologists; $\mathrm{ODI}=$ Oswestry Disability Index; PRO = patient-reported outcome; $Q O D=Q$ Quality Outcomes Database; $\mathrm{VA}=$ Veterans Affairs; VAS = visual analog scale.

SUBMITTED March 8, 2018. ACCEPTED July 11, 2018.

INCLUDE WHEN CITING Published online November 2, 2018; DOI: 10.3171/2018.7.SPINE18294. 
stenosis surgery. It is important for spine care providers to understand factors affecting their patients' outcomes and the nature of possible indirect influences on their results. The rationale for combining VA- and Medicare-insured patients is that both forms of insurance are public in the US, and this study's goal was to explore differences between patients with private insurance and those with public insurance. In particular, the purpose of this study was to explore the relationship of insurance status on PROs at 12 months after decompression surgery and subsequent indicated treatment, as evaluated at a single, high-volume academic institution in the Southeastern US.

\section{Methods \\ Data Collection}

Data were collected as part of a prospective observational registry (Quality Outcomes Database [QOD]) that documents morbidity, mortality, and PROs at baseline and 3 and 12 months postintervention. The methodology for data collection, abstraction, and implementation has been published in detail previously $y^{3,4,20}$ and involves prospective collection of specific data points encompassing patient characteristics, treatment, and outcome. Research coordinators at our institution entered the data via a secure web portal, the "Research Electronic Data Capture" system, or "REDCap" (REDCap, Vanderbilt University). ${ }^{16}$

As previously reported, ${ }^{11}$ primary criteria for inclusion in the database are lumbar location, degenerative disease, disc herniation, spinal stenosis, grade 1 spondylolisthesis, disc collapse, and adjacent-segment disease. There are multiple rounds of exclusion criteria to consider. Patients are initially excluded on general characteristics such as tumors, infections, traumatic fractures, patient incarceration, age younger than 18 years, or unobtained consent, or if the surgeon does not participate in the QOD. Lumbar-specific criteria encompass the second round of exclusions, including grade 2-4 spondylolisthesis, ossification of the posterior longitudinal ligament, deformity, sacroiliac joint fusion, paralysis, patient cognitive/psychiatric impairment, severe peripheral neuropathy, and complex regional pain syndrome. The final exclusion criteria are administrative, with all enrolled patients needing sufficient documentation and follow-up to warrant consideration. The enrollments are done on a 6-day accrual cycle, with a new set of patients considered weekly. Only the first 6 eligible patients within a particular cycle are enrolled, and patients are never deferred to the next cycle if they do not achieve enrollment during their selected period.

The database for this study was formulated by exporting specific results from the collection in a de-identified manner to protect patient privacy. No individually identifiable data were extracted, in compliance with HIPAA directives. Our IRB considers the use of this data collection exempt from IRB review, due to a previous review of the methodologies involved and its use for functional outcomes and quality assurance research.

\section{Study Design}

The prospectively gathered data from a single, highvolume academic institution in the Southeastern US were used to assess patients who underwent surgery for a primary diagnosis of lumbar spinal stenosis and for whom payer status-private insurance compared with Medicare or VA insurance-was documented. All patients were treated at the same university center; none were treated at a VA hospital. The aims were to 1) assess baseline functional outcomes and postintervention functional outcomes and 2) determine the role of previously described covariates and their potential as significant prognostic indicators or confounders. This study queried a prospective observational registry of lumbar spinal stenosis patients enrolled from February 2012 to June 2014. Patients were stratified into 2 cohorts: those with private insurance at baseline and those with forms of public insurance (Medicare or VA insurance).

\section{Study Measures}

Four metrics were used as patient-reported functional outcomes at baseline and 3 months and 12 months postintervention: back and leg pain based on the visual analog scale (VAS), EQ-5D, and Oswestry Disability Index (ODI).

\section{Statistical Analysis}

Parametric data are given as the mean \pm standard deviation and were compared using the Student t-test; related parametric data sets are given as the mean \pm standard deviation using a paired t-test. Determination of normality was performed using the Shapiro-Wilk test. Nominal/ categorical data were compared using Fisher's exact test. Statistical significance was defined as $\mathrm{p}<0.05$ for all analyses. Statistical analyses were performed using IBM SPSS (version 23.0, IBM Corp.). Multivariate analysis was accomplished using multiple regression models with continuous dependent variables and categorical independent variables. Comparative analyses of the 2 groups were performed at baseline and 3 and 12 months postoperatively, both with and without VA-insured patients included. Specific covariates were identified as confounders in the SPORT trial (Spine Patient Outcomes Research Trial). ${ }^{17}$ These included age (stratified by decade), sex, smoking status, diabetes, depression, BMI, American Society of Anesthesiologists (ASA) Physical Status Classification class, level of education, and ambulation category. The multiple regression analyses were performed using RStudio (version 0.99.902, RStudio) and $\mathrm{R}$ programming language (version 3.2.3, The R Foundation).

\section{Results}

\section{Baseline Patient Characteristics}

A sample of 100 patients were selected for this prospective observational cohort study with functional outcomes data at 3 months postintervention; 77 of these patients also had outcomes data at 12 months postintervention. No patient in our analysis had Medicaid insurance. Primary insurance only was considered. The presence of dual insurance, i.e., having both private insurance and Medicare, was not known in this population. Baseline patient characteristics are presented in Table 1.

Statistically significant differences were noted between patient populations with regard to age, ambulation 
TABLE 1. Baseline patient characteristics

\begin{tabular}{|c|c|c|c|}
\hline & $\begin{array}{l}\text { Private Insurance } \\
\qquad(\mathrm{n}=46)\end{array}$ & $\begin{array}{l}\text { Gov Insurance } \\
\quad(n=54)\end{array}$ & $\begin{array}{c}p \\
\text { Value }\end{array}$ \\
\hline Mean age, yrs & $54.30 \pm 9.01$ & $67.91 \pm 13.06$ & $<0.001$ \\
\hline Mean BMI & $28.83 \pm 7.84$ & $28.74 \pm 5.00$ & 0.941 \\
\hline \multicolumn{4}{|l|}{ Sex } \\
\hline Male & $24(52.17)$ & $39(72.22)$ & 0.062 \\
\hline Female & $22(47.83)$ & $15(27.78)$ & 0.062 \\
\hline \multicolumn{4}{|l|}{ Insurance payer } \\
\hline Medicare & $0(0.00)$ & $46(85.19)$ & \\
\hline Medicaid & $0(0.00)$ & $0(0.00)$ & \\
\hline Private & $46(100.00)$ & $0(0.00)$ & \\
\hline VA/gov & $0(0.00)$ & $8(14.81)$ & \\
\hline \multicolumn{4}{|l|}{ Smoking status } \\
\hline $\begin{array}{l}\text { Current every day or } \\
\text { almost daily }\end{array}$ & $10(21.74)$ & $9(16.67)$ & 0.696 \\
\hline $\begin{array}{l}\text { Current some days or } \\
\text { occasional }\end{array}$ & $0(0.00)$ & $1(1.85)$ & $>0.99$ \\
\hline $\begin{array}{l}\text { Unknown if currently } \\
\text { smoking }\end{array}$ & $0(0.00)$ & $0(0.00)$ & $>0.99$ \\
\hline No & $36(78.26)$ & $44(81.48)$ & 0.878 \\
\hline \multicolumn{4}{|l|}{ Diabetes } \\
\hline $\begin{array}{l}\text { Type 2, non-insulin } \\
\text { dependent }\end{array}$ & $3(6.52)$ & $7(12.96)$ & 0.466 \\
\hline $\begin{array}{l}\text { Type 2, insulin depen- } \\
\text { dent }\end{array}$ & $1(2.17)$ & $4(7.41)$ & 0.47 \\
\hline $\begin{array}{l}\text { Type 1, insulin depen- } \\
\text { dent }\end{array}$ & $0(0.00)$ & $0(0.00)$ & $>0.99$ \\
\hline No & $42(91.30)$ & $43(79.63)$ & 0.175 \\
\hline \multicolumn{4}{|l|}{ Depression disorder } \\
\hline Yes & $7(15.22)$ & $10(18.52)$ & 0.868 \\
\hline No & $39(84.78)$ & $44(81.48)$ & 0.868 \\
\hline \multicolumn{4}{|l|}{ Ambulation category } \\
\hline Independent & $39(84.78)$ & $42(77.78)$ & 0.032 \\
\hline Wheelchair-bound & $0(0.00)$ & $1(1.85)$ & $>0.99$ \\
\hline Assist device & $2(4.35)$ & $11(20.37)$ & 0.054 \\
\hline \multicolumn{4}{|l|}{ Ethnicity } \\
\hline Asian & $1(2.17)$ & $1(1.85)$ & $>0.99$ \\
\hline $\begin{array}{c}\text { Black or African } \\
\text { American }\end{array}$ & $2(4.35)$ & $6(11.11)$ & 0.386 \\
\hline White & $43(93.48)$ & $46(85.19)$ & 0.318 \\
\hline Other & $0(0.00)$ & $1(1.85)$ & $>0.99$ \\
\hline \multicolumn{4}{|l|}{ Coronary artery disease } \\
\hline Yes & $1(2.17)$ & $2(3.70)$ & $>0.99$ \\
\hline No & $45(97.83)$ & $52(96.30)$ & $>0.99$ \\
\hline \multicolumn{4}{|l|}{ Any cardiovascular issue } \\
\hline Yes & $1(2.17)$ & $2(3.70)$ & $>0.99$ \\
\hline No & $45(97.83)$ & $52(96.30)$ & $>0.99$ \\
\hline \multicolumn{4}{|l|}{ Osteoporosis } \\
\hline Yes & $1(2.17)$ & $1(1.85)$ & $>0.99$ \\
\hline No & $45(97.83)$ & $53(98.15$ & $>0.99$ \\
\hline
\end{tabular}

» CONTINUED FROM PREVIOUS COLUMN

TABLE 1. Baseline patient characteristics

\begin{tabular}{|c|c|c|c|}
\hline & $\begin{array}{l}\text { Private Insurance } \\
\qquad(n=46)\end{array}$ & $\begin{array}{l}\text { Gov Insurance } \\
\quad(n=54)\end{array}$ & $\begin{array}{c}p \\
\text { Value }\end{array}$ \\
\hline \multicolumn{4}{|l|}{ Dementia } \\
\hline Yes & $0(0.00)$ & $0(0.00)$ & $>0.99$ \\
\hline No & $46(100.00)$ & $54(100.00)$ & \\
\hline \multicolumn{4}{|l|}{ Level of education } \\
\hline $\begin{array}{l}\text { High school diploma } \\
\text { or GED }\end{array}$ & $12(26.09)$ & $12(22.22)$ & 0.827 \\
\hline Less than high school & $1(2.17)$ & $1(1.85)$ & $>0.99$ \\
\hline 2-yr college degree & $8(17.39)$ & $9(16.67)$ & $>0.99$ \\
\hline 4-yr college degree & $14(30.43)$ & $15(27.78)$ & 0.942 \\
\hline Post-college & $11(23.91)$ & $17(31.48)$ & 0.539 \\
\hline \multicolumn{4}{|l|}{$\begin{array}{c}\text { ASA class (per anesthe- } \\
\text { sia operative report) }\end{array}$} \\
\hline 1 & $3(6.52)$ & $0(0.00)$ & 0.188 \\
\hline II & $21(45.65)$ & $5(9.26)$ & $<0.001$ \\
\hline III & $22(47.83)$ & $48(88.89)$ & $<0.001$ \\
\hline IV & $0(0.00)$ & $1(1.85)$ & $>0.99$ \\
\hline \multicolumn{4}{|l|}{$\begin{array}{l}\text { No. of levels decom- } \\
\text { pressed }\end{array}$} \\
\hline 1 & $20(43.48)$ & $12(22.22)$ & 0.04 \\
\hline 2 & $18(39.13)$ & $24(44.44)$ & 0.74 \\
\hline 3 & $7(15.22)$ & $11(20.37)$ & 0.687 \\
\hline 4 & $0(0.00)$ & $6(11.11)$ & 0.043 \\
\hline \multicolumn{4}{|l|}{$\begin{array}{l}\text { No. of levels arthrodesis } \\
\text { performed }\end{array}$} \\
\hline 1 & $3(6.52)$ & $2(3.70)$ & 0.848 \\
\hline 2 & $1(2.17)$ & $3(5.56)$ & 0.743 \\
\hline 3 & $0(0.00)$ & $0(0.00)$ & 1.000 \\
\hline 4 & $0(0.00)$ & $0(0.00)$ & 1.000 \\
\hline \multicolumn{4}{|l|}{ Major op in the past yr } \\
\hline Cervical & $3(6.52)$ & $2(3.70)$ & 0.827 \\
\hline Thoracolumbar & $2(4.35)$ & $2(3.70)$ & $>0.99$ \\
\hline Hip & $0(0.00)$ & $0(0.00)$ & $>0.99$ \\
\hline Knee & $0(0.00)$ & $2(3.70)$ & 0.590 \\
\hline Other & $0(0.00)$ & $1(1.85)$ & $>0.99$ \\
\hline $\begin{array}{l}\text { Mean estimated blood } \\
\text { loss, } \mathrm{ml}\end{array}$ & $80.00 \pm 67.57$ & $76.63 \pm 58.93$ & 0.854 \\
\hline \multicolumn{4}{|l|}{$\begin{array}{l}\text { Duration of longest- } \\
\text { standing spine } \\
\text { symptoms, mos }\end{array}$} \\
\hline$>3$ & $41(89.13)$ & 50 (92.59) & 0.797 \\
\hline$<3$ & $5(10.87)$ & $3(5.56)$ & 0.543 \\
\hline Unknown & $0(0.00)$ & $1(1.85)$ & $>0.99$ \\
\hline \multicolumn{4}{|l|}{$\begin{array}{l}\text { Any motor deficits related } \\
\text { to spine diagnosis }\end{array}$} \\
\hline Yes & $4(8.70)$ & $8(14.81)$ & 0.513 \\
\hline No & $41(89.13)$ & $44(81.48)$ & 0.513 \\
\hline
\end{tabular}

GED = General Educational Development; gov = government.

Values are presented as the number of patients (\%) unless stated otherwise. Mean values are presented as the mean \pm SD. Boldface type indicates statistical significance. 
TABLE 2. Four functional outcomes: government versus private insurance

\begin{tabular}{|c|c|c|c|c|c|}
\hline & Private $(n=46)$ & Gov $(n=54)$ & Mean Difference & $95 \% \mathrm{Cl}$ & p Value \\
\hline \multicolumn{6}{|c|}{ Back pain $(0-10)$ over the past 7 days } \\
\hline Baseline & $6.80 \pm 2.42$ & $6.74 \pm 2.60$ & 0.06 & -0.92 to 1.05 & 0.901 \\
\hline $3 \mathrm{mos}$ & $1.83 \pm 2.40$ & $2.66 \pm 2.41$ & 0.83 & -0.25 to 1.91 & 0.143 \\
\hline $12 \mathrm{mos}$ & $2.52 \pm 2.62$ & $3.12 \pm 2.95$ & 0.6 & -0.80 to 2.00 & 0.427 \\
\hline \multicolumn{6}{|c|}{ Leg pain $(0-10)$ over the past 7 days } \\
\hline Baseline & $6.63 \pm 2.65$ & $7.09 \pm 2.53$ & 0.46 & -0.56 to 1.48 & 0.38 \\
\hline 3 mos & $1.69 \pm 2.01$ & $2.95 \pm 3.21$ & 1.26 & 0.07 to 2.46 & 0.051 \\
\hline $12 \mathrm{mos}$ & $2.04 \pm 2.16$ & $2.70 \pm 2.94$ & 0.66 & -0.61 to 1.92 & 0.361 \\
\hline \multicolumn{6}{|c|}{ Total EQ-5D score } \\
\hline Baseline & $0.54 \pm 0.22$ & $0.54 \pm 0.23$ & 0.01 & -0.08 to 0.09 & 0.908 \\
\hline 3 mos & $0.84 \pm 0.19$ & $0.73 \pm 0.23$ & 0.11 & 0.02 to 0.21 & $<0.001$ \\
\hline $12 \mathrm{mos}$ & $0.87 \pm 0.14$ & $0.74 \pm 0.21$ & 0.14 & 0.05 to 0.22 & $<0.001$ \\
\hline \multicolumn{6}{|c|}{ Total ODI sum score } \\
\hline Baseline & $45.09 \pm 16.69$ & $43.67 \pm 14.92$ & 1.42 & -4.83 to 7.67 & 0.658 \\
\hline $3 \mathrm{mos}$ & $16.91 \pm 19.67$ & $22.76 \pm 18.24$ & 5.85 & -2.69 to 14.39 & 0.186 \\
\hline $12 \mathrm{mos}$ & $14.67 \pm 15.27$ & $21.32 \pm 18.56$ & 6.65 & -1.69 to 14.99 & 0.149 \\
\hline
\end{tabular}

Values are presented as the mean \pm SD unless noted otherwise. Boldface type indicates statistical significance.

category, ASA class, and number of laminectomy levels. There were no statistically significant differences between groups regarding BMI, sex, smoking status, diabetes, depression, education, presence of major surgery in the past year, or duration of symptoms (Table 1). The mean blood loss for surgery was defined for both cohorts. Although it is unclear whether any patient underwent emergency surgery, the overwhelming majority of patients experienced longer than 3 months of symptoms, and the surgeries were presumably elective in nature. A small percentage of patients underwent fusion. The typical indication for arthrodesis at our institution includes the presence of instability on preoperative examination or radiographs. Occasionally, the extent of bony decompression required to free neural elements destabilizes the spine, therefore necessitating arthrodesis.

\section{Patient-Reported Functional Outcomes}

At baseline, there were no significant differences in terms of function between patients with private and those with government insurance. However, at 3 and 12 months postintervention, patients with private insurance had EQ$5 \mathrm{D}$ scores that were superior to those with government insurance, as reflected in Table 2.

Between time points, the private insurance cohort tended to have continued improvement in their back and leg pain between 3 months and 12 months postintervention, a finding not exhibited by the government insurance cohort. ODI and EQ-5D scores reached their maximal improvement at 3 months postintervention for the private insurance cohort (Table 3 ).

Analysis of the 4 PROs was repeated with VA-insured patients excluded (Table 4). Once again, it was found that the private insurance carriers had a significant improvement in EQ-5D scores, and therefore quality of life, compared with their Medicare counterparts at 1 year postop- eratively. Conversely, there were no statistically significant differences in reported back pain, leg pain, or disability between the 2 cohorts across all time points.

\section{Multivariate Analysis}

At baseline, multiple regression analysis suggested that payer status was not associated with a statistically significant difference in most of the 4 patient-reported metrics, with the exception of less leg pain in the government-insured cohort. Depression, BMI > 25, and lower education level were associated with worse back pain at baseline. Daily smoking and assistance with a wheelchair were associated with increased reported levels of disability at baseline. Smoking, depression, and wheelchair confinement were associated with worse quality of life at baseline (Table 5). At 3 months, private insurance had an association with decreased leg pain and increased quality of life (Table 6). At 12 months postintervention, private insurance and post-college education had an association with less back pain and increased quality of life. Post-college education also showed significantly decreased disability. Meanwhile, wheelchair-bound patients had worse leg pain and decreased quality of life (Table 7). When VA-insured patients were excluded from the analysis, privately insured patients once again demonstrated less back pain and increased quality of life (Table 8).

\section{Discussion}

Several studies have considered insurance disparities in patient outcomes after lumbar spinal surgery, comparing those with government insurance (Medicare, Medicaid, and VA) and those with private insurance. ${ }^{6-8,18,21}$ None, however, have specifically considered differences in a primarily Medicare/VA insured population and those with private insurance. We therefore sought to compare these 
TABLE 3. Paired functional outcomes based on time: government versus private insurance

\begin{tabular}{|c|c|c|c|c|c|c|}
\hline & Private $(n=35)^{*}$ & $95 \% \mathrm{Cl}$ & $p$ Value & $\operatorname{Gov}(n=42)^{*}$ & $95 \% \mathrm{Cl}$ & p Value \\
\hline \multicolumn{7}{|c|}{ Back pain $(0-10)$ over the past 7 days } \\
\hline Baseline vs 3 mos & $5.09 \pm 2.93$ & 4.12 to 6.06 & $<0.001$ & $4.41 \pm 3.32$ & 3.41 to 5.41 & $<0.001$ \\
\hline Baseline vs 12 mos & $3.74 \pm 3.34$ & 2.63 to 4.85 & $<0.001$ & $4.05 \pm 3.44$ & 3.01 to 5.09 & $<0.001$ \\
\hline 3 mos vs 12 mos & $-1.32 \pm 2.36$ & -2.10 to -0.54 & $<0.001$ & $-0.48 \pm 3.09$ & -1.41 to 0.45 & 0.381 \\
\hline \multicolumn{7}{|c|}{ Leg pain $(0-10)$ over the past 7 days } \\
\hline Baseline vs 3 mos & $5.29 \pm 2.66$ & 4.41 to 6.17 & $<0.001$ & $4.33 \pm 3.88$ & 3.16 to 5.50 & $<0.001$ \\
\hline Baseline vs 12 mos & $4.43 \pm 3.35$ & 3.32 to 5.54 & $<0.001$ & $4.65 \pm 3.41$ & 3.62 to 5.68 & $<0.001$ \\
\hline 3 mos vs 12 mos & $-1.37 \pm 2.52$ & -2.20 to -0.54 & $<0.001$ & $0.31 \pm 2.89$ & -0.56 to 1.18 & 0.551 \\
\hline \multicolumn{7}{|l|}{ Total ODI sum score } \\
\hline Baseline vs 3 mos & $30.40 \pm 17.50$ & 24.60 to 36.20 & $<0.001$ & $21.10 \pm 14.83$ & 16.6 to 25.59 & $<0.001$ \\
\hline Baseline vs 12 mos & $26.25 \pm 16.23$ & 20.87 to 31.63 & $<0.001$ & $23.27 \pm 16.82$ & 18.18 to 28.36 & $<0.001$ \\
\hline 3 mos vs 12 mos & $-5.00 \pm 14.76$ & -9.89 to -0.11 & 0.156 & $1.45 \pm 14.93$ & -3.07 to 5.97 & 0.585 \\
\hline \multicolumn{7}{|l|}{ Total EQ-5D score } \\
\hline Baseline vs 3 mos & $-0.35 \pm 0.21$ & -0.42 to -0.28 & $<0.001$ & $-0.19 \pm 0.26$ & -0.27 to -0.11 & $<0.001$ \\
\hline Baseline vs 12 mos & $-0.30 \pm 0.19$ & -0.36 to -0.24 & $<0.001$ & $-0.21 \pm 0.25$ & -0.29 to -0.13 & $<0.001$ \\
\hline 3 mos vs 12 mos & $0.05 \pm 0.17$ & -0.01 to 0.11 & 0.261 & $0.02 \pm 0.18$ & -0.03 to 0.07 & 0.548 \\
\hline
\end{tabular}

Boldface type indicates statistical significance.

*Values are mean $( \pm S D)$ changes between the time points. A negative value for back and leg pain indicates higher levels of pain. A negative value for ODI and EQ-5D indicates improvement in quality of life.

groups according to 4 PROs after lumbar spinal stenosis surgery.

\section{Interpretation of Results}

In our population, the groups were similar at baseline before surgery with regard to patient-reported VAS back and leg pain scores, ODI scores, and EQ-5D scores. They differed with respect to older age, worse ambulation status, and higher ASA classes identified in the government insurance cohort. This is expected, as the government- insured cohort comprised Medicare recipients, who are required to be older than 65 years for inclusion, with subsequently more comorbidities. However, multiple regression analysis did not reveal statistical significance between the variables of age, ASA class, or independent ambulation status and the 4 PROs. Baseline characteristics of BMI, sex, smoking status, diabetes, depression, level of education, and duration of symptoms, which have been listed previously as potential confounders, ${ }^{1,5,27}$ were similar between the 2 groups in our study.

TABLE 4. Four functional outcomes in private versus Medicare payer status

\begin{tabular}{|c|c|c|c|c|c|}
\hline & Private $(n=46)$ & Medicare $(n=46)$ & Mean Difference & $95 \% \mathrm{Cl}$ & $\mathrm{p}$ Value \\
\hline \multicolumn{6}{|c|}{ Back pain $(0-10)$ over the past 7 days } \\
\hline Baseline & $6.80 \pm 2.42$ & $6.65 \pm 2.68$ & 0.15 & -0.89 to 1.20 & 0.778 \\
\hline 3 mos & $1.83 \pm 2.40$ & $2.63 \pm 2.27$ & 0.8 & -0.29 to 1.89 & 0.162 \\
\hline $12 \mathrm{mos}$ & $2.52 \pm 2.62$ & $3.25 \pm 2.94$ & 0.73 & -0.71 to 2.17 & 0.345 \\
\hline \multicolumn{6}{|c|}{ Leg pain $(0-10)$ over the past 7 days } \\
\hline Baseline & $6.63 \pm 2.65$ & $7.26 \pm 2.34$ & 0.63 & -0.39 to 1.65 & 0.235 \\
\hline 3 mos & $1.69 \pm 2.01$ & $2.79 \pm 3.22$ & 1.11 & -0.16 to 2.38 & 0.094 \\
\hline $12 \mathrm{mos}$ & $2.04 \pm 2.16$ & $2.69 \pm 2.87$ & 0.64 & -0.65 to 1.94 & 0.371 \\
\hline \multicolumn{6}{|c|}{ Total EQ-5D score } \\
\hline Baseline & $0.54 \pm 0.22$ & $0.54 \pm 0.22$ & 0 & -0.09 to 0.09 & 0.972 \\
\hline 3 mos & $0.84 \pm 0.19$ & $0.75 \pm 0.22$ & 0.09 & -0.00 to 0.19 & 0.07 \\
\hline $12 \mathrm{mos}$ & $0.87 \pm 0.14$ & $0.74 \pm 0.22$ & 0.14 & 0.05 to 0.23 & $<0.001$ \\
\hline \multicolumn{6}{|c|}{ Total ODI sum score } \\
\hline Baseline & $45.09 \pm 16.69$ & $42.91 \pm 14.59$ & 2.17 & -4.23 to 8.58 & 0.512 \\
\hline 3 mos & $16.91 \pm 19.67$ & $21.20 \pm 15.80$ & 4.29 & -4.07 to 12.64 & 0.325 \\
\hline $12 \mathrm{mos}$ & $14.67 \pm 15.27$ & $20.50 \pm 17.37$ & 5.83 & -2.50 to 14.17 & 0.194 \\
\hline
\end{tabular}

Boldface type indicates statistical significance. VA-insured patients are excluded. Values are presented as the mean \pm SD unless noted otherwise. 
TABLE 5. Baseline functional outcomes: multiple regression

\begin{tabular}{|c|c|c|c|c|}
\hline & \multicolumn{4}{|c|}{ Dependent Variable } \\
\hline & $\begin{array}{l}\text { Back } \\
\text { Pain }\end{array}$ & $\begin{array}{l}\text { Leg } \\
\text { Pain }\end{array}$ & $\begin{array}{l}\text { ODI } \\
\text { Score }\end{array}$ & $E Q-5 D$ \\
\hline \multicolumn{5}{|l|}{ Age, yrs } \\
\hline \multirow{2}{*}{$40-50$} & -0.765 & -0.884 & -9.949 & 0.170 \\
\hline & $(1.528)$ & $(1.631)$ & (8.624) & $(0.126)$ \\
\hline \multirow{2}{*}{$50-60$} & -1.466 & -1.488 & $-14.242^{*}$ & 0.184 \\
\hline & $(1.462)$ & $(1.561)$ & (8.251) & $(0.121)$ \\
\hline \multirow{2}{*}{$60-70$} & -1.107 & -1.486 & -9.713 & $0.244^{*}$ \\
\hline & $(1.544)$ & (1.648) & $(8.715)$ & $(0.127)$ \\
\hline \multirow{2}{*}{$70-80$} & -1.482 & -0.975 & $-18.084^{*}$ & 0.103 \\
\hline & $(1.704)$ & $(1.819)$ & $(9.616)$ & $(0.141)$ \\
\hline \multirow{2}{*}{ Male sex } & -0.510 & -0.374 & -3.807 & 0.048 \\
\hline & $(0.659)$ & $(0.704)$ & (3.721) & $(0.054)$ \\
\hline \multicolumn{5}{|l|}{ Smoker } \\
\hline \multirow{2}{*}{ Everyday } & -0.434 & 0.719 & $10.276^{* *}$ & $-0.149^{* *}$ \\
\hline & $(0.788)$ & $(0.841)$ & $(4.447)$ & $(0.065)$ \\
\hline \multirow{2}{*}{$\begin{array}{l}\text { Some days or oc- } \\
\text { casional }\end{array}$} & -1.405 & -0.343 & $-35.433^{* *}$ & 0.005 \\
\hline & $(2.739)$ & $(2.924)$ & (15.458) & $(0.226)$ \\
\hline \multicolumn{5}{|l|}{ Diabetes type 2} \\
\hline \multirow{2}{*}{ Insulin dependent } & 1.952 & 0.117 & 4.347 & -0.176 \\
\hline & $(1.308)$ & $(1.396)$ & $(7.380)$ & $(0.108)$ \\
\hline \multirow{2}{*}{$\begin{array}{l}\text { Non-insulin depen- } \\
\text { dent }\end{array}$} & 1.140 & 0.546 & -7.493 & 0.080 \\
\hline & $(1.085)$ & $(1.158)$ & $(6.122)$ & $(0.090)$ \\
\hline \multirow{2}{*}{ Depression disorder } & $1.935^{\star *}$ & $1.499^{*}$ & 4.673 & $-0.148^{* *}$ \\
\hline & $(0.808)$ & $(0.862)$ & $(4.559)$ & $(0.067)$ \\
\hline \multicolumn{5}{|l|}{ BMI } \\
\hline \multirow{2}{*}{$20-25$} & 2.444 & -0.645 & -6.135 & 0.136 \\
\hline & $(1.662)$ & $(1.774)$ & $(9.377)$ & $(0.137)$ \\
\hline \multirow{2}{*}{$25-30$} & $3.725^{\star *}$ & -1.236 & 0.139 & 0.168 \\
\hline & $(1.576)$ & (1.682) & (8.892) & $(0.130)$ \\
\hline \multirow{2}{*}{$30-35$} & $4.275^{\star *}$ & -0.360 & 6.437 & -0.039 \\
\hline & $(1.755)$ & $(1.873)$ & $(9.902)$ & $(0.145)$ \\
\hline \multirow{2}{*}{$\geq 35$} & $4.202^{* *}$ & -0.957 & 2.846 & 0.026 \\
\hline & $(1.886)$ & $(2.013)$ & $(10.644)$ & $(0.156)$ \\
\hline \multicolumn{5}{|l|}{ Level of education } \\
\hline \multirow{2}{*}{$\begin{array}{l}\text { High school or } \\
\text { GED }\end{array}$} & $2.273^{* * *}$ & $2.121^{* *}$ & 0.869 & -0.098 \\
\hline & $(0.756)$ & $(0.807)$ & (4.265) & $(0.062)$ \\
\hline \multirow{2}{*}{$\begin{array}{l}\text { Less than high } \\
\text { school }\end{array}$} & $3.918^{* *}$ & 0.331 & 7.848 & $-0.303^{*}$ \\
\hline & (1.901) & $(2.029)$ & $(10.729)$ & $(0.157)$ \\
\hline \multirow{2}{*}{ Post-college } & 0.661 & 0.590 & -2.925 & -0.074 \\
\hline & $(0.710)$ & $(0.758)$ & $(4.008)$ & $(0.059)$ \\
\hline 2 urcollogo dearen & 0.881 & 1.292 & 6.854 & -0.063 \\
\hline 2-yr college aegree & $(0.912)$ & $(0.973)$ & $(5.146)$ & $(0.075)$ \\
\hline $\begin{array}{l}\text { Ambulation classifica- } \\
\text { tion }\end{array}$ & & & & \\
\hline nendent & 1.373 & -0.571 & $-11.615^{*}$ & 0.016 \\
\hline maependuent & $(1.223)$ & $(1.305)$ & (6.902) & $(0.101)$ \\
\hline Wheelchair- & 3.887 & 0.391 & $38.584^{* *}$ & $-0.663^{* * *}$ \\
\hline bound & $(2.806)$ & (2.995) & $(15.833)$ & $(0.232)$ \\
\hline
\end{tabular}

CONTINUED IN NEXT COLUMN »
» CONTINUED FROM PREVIOUS COLUMN

TABLE 5. Baseline functional outcomes: multiple regression

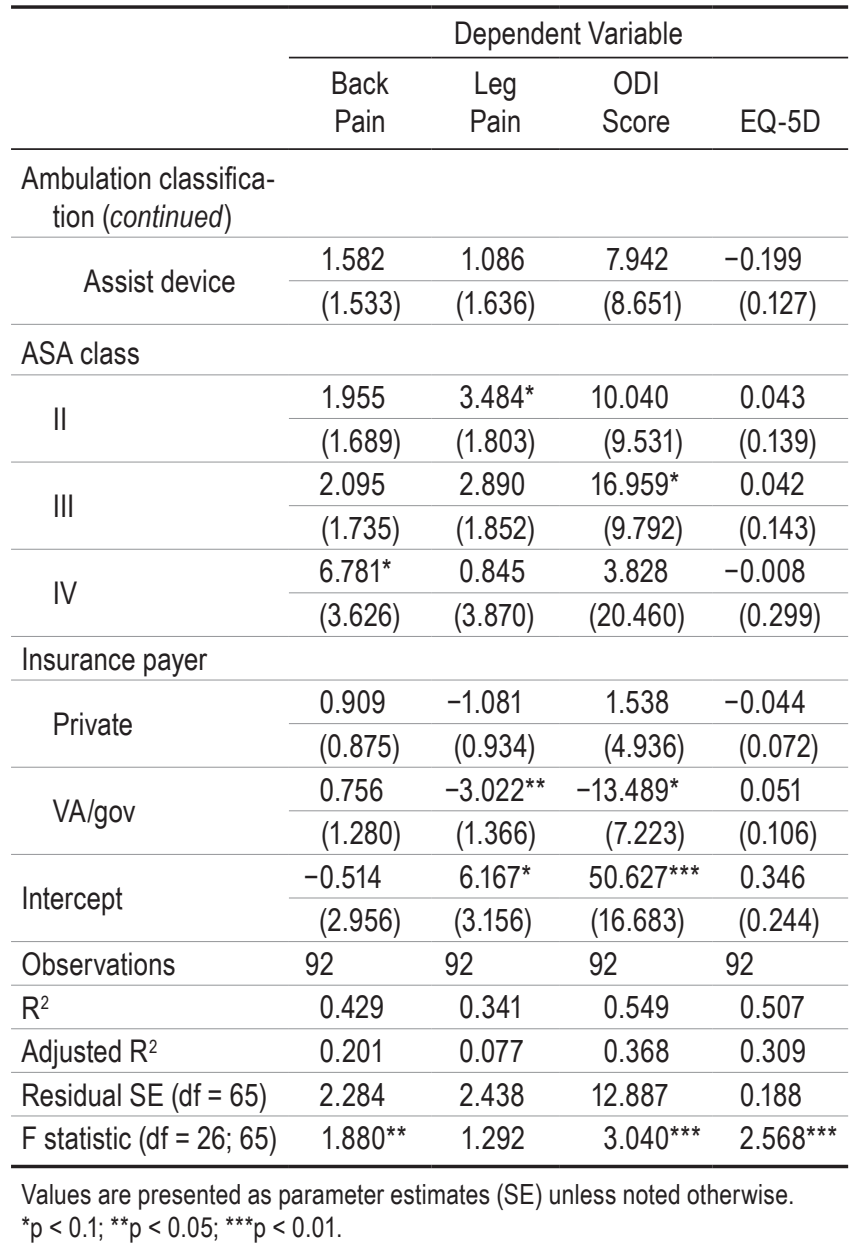

We found that at 3 months, patients with Medicare/ VA insurance reported persistent leg pain (which neared, but did not reach, significance, $p=0.051$ ) and lower quality of life scores than those with private insurance. Our outcomes data at 3 months for the government cohort regarding leg pain likely did not reach significance because the data were underpowered to find a difference. At 12 months, those with Medicare/VA insurance still reported worse quality of life than those with private insurance. This suggests that the Medicare/VA population takes longer to recover after surgery, but will reach equivalency with the private cohort at 12 months with regard to back pain, leg pain, and ODI. Both cohorts met the minimum clinically important difference in ODI, back pain, and leg pain scores, as previously described by Copay et al. ${ }^{9} \mathrm{~Pa}-$ tients with government insurance do, however, continue to report worse quality of life after elective lumbar spinal surgery than those patients with private insurance. One may assign this difference in quality of life after surgery to the statistically significant difference in preoperative age between the private insurance and government insurance cohorts. This is in contrast to the findings of McGirt et al., who reported that patients older and younger than 70 years had equivalent outcomes after surgery for lumbar stenosis 
TABLE 6. Postoperative functional outcomes at 3 months: multiple regression

\begin{tabular}{|c|c|c|c|c|}
\hline & \multicolumn{4}{|c|}{ Dependent Variable } \\
\hline & Back Pain & Leg Pain & ODI Score & $E Q-5 D$ \\
\hline \multicolumn{5}{|l|}{ Age, yrs } \\
\hline \multirow{2}{*}{$40-50$} & -2.311 & -3.083 & -18.104 & $0.246^{*}$ \\
\hline & $(1.706)$ & $(1.869)$ & $(13.133)$ & $(0.146)$ \\
\hline \multirow{2}{*}{$50-60$} & -0.822 & -2.327 & -10.197 & 0.200 \\
\hline & $(1.565)$ & $(1.716)$ & $(12.146)$ & $(0.134)$ \\
\hline \multirow{2}{*}{$60-70$} & -2.146 & $-4.600^{* *}$ & $-23.362^{*}$ & $0.314^{* *}$ \\
\hline & $(1.753)$ & $(1.920)$ & $(13.512)$ & $(0.151)$ \\
\hline \multirow{2}{*}{$70-80$} & -3.200 & $-6.710^{* * *}$ & $-31.231^{* *}$ & $0.343^{* *}$ \\
\hline & $(1.956)$ & $(2.153)$ & $(15.154)$ & $(0.168)$ \\
\hline \multirow{2}{*}{ Male sex } & 0.654 & 0.671 & 2.378 & -0.081 \\
\hline & $(0.861)$ & $(0.951)$ & (6.635) & $(0.072)$ \\
\hline \multicolumn{5}{|l|}{ Smoking status } \\
\hline \multirow{2}{*}{ Everyday } & -0.215 & 0.949 & 3.505 & -0.039 \\
\hline & $(0.953)$ & $(1.046)$ & (7.418) & $(0.082)$ \\
\hline \multirow{2}{*}{ Occasional } & -1.376 & $-7.119^{* *}$ & -32.229 & 0.102 \\
\hline & (3.133) & $(3.432)$ & $(23.244)$ & $(0.269)$ \\
\hline \multicolumn{5}{|l|}{ Diabetes type 2} \\
\hline \multirow{2}{*}{ Insulin dependent } & 0.608 & -0.457 & 4.995 & -0.087 \\
\hline & $(1.734)$ & $(1.905)$ & $(13.476)$ & $(0.149)$ \\
\hline \multirow{2}{*}{ Non-insulin dependent } & 0.307 & -1.011 & -2.825 & 0.073 \\
\hline & $(1.314)$ & $(1.454)$ & $(10.129)$ & $(0.113)$ \\
\hline \multirow{2}{*}{ Depression disorder, yes } & 1.135 & 0.774 & 3.994 & -0.037 \\
\hline & $(1.153)$ & $(1.263)$ & (7.759) & $(0.099)$ \\
\hline \multicolumn{5}{|l|}{ BMI } \\
\hline \multirow{2}{*}{$20-25$} & 1.244 & 3.344 & 20.375 & -0.075 \\
\hline & $(2.237)$ & $(2.450)$ & $(14.964)$ & $(0.192)$ \\
\hline \multirow{2}{*}{$25-30$} & 1.104 & 1.321 & 13.163 & 0.098 \\
\hline & (2.127) & (2.331) & $(13.509)$ & $(0.182)$ \\
\hline \multirow{2}{*}{$30-35$} & 0.823 & 2.875 & 14.693 & 0.197 \\
\hline & (2.345) & (2.571) & $(15.157)$ & $(0.200)$ \\
\hline \multirow{2}{*}{$\geq 35$} & 2.312 & 0.716 & 19.509 & 0.068 \\
\hline & (2.399) & (2.631) & $(16.259)$ & $(0.205)$ \\
\hline \multicolumn{5}{|l|}{ Level of education } \\
\hline \multirow{2}{*}{ High school or GED } & 0.291 & -1.109 & -0.805 & 0.010 \\
\hline & $(0.904)$ & $(1.009)$ & (6.954) & $(0.077)$ \\
\hline \multirow{2}{*}{ Less than high school } & 1.474 & $-4.016^{*}$ & -2.483 & 0.275 \\
\hline & $(2.089)$ & $(2.289)$ & $(16.166)$ & $(0.178)$ \\
\hline \multirow{2}{*}{ Post-college } & 0.789 & -0.420 & -3.121 & 0.095 \\
\hline & $(0.942)$ & $(1.032)$ & (7.222) & $(0.079)$ \\
\hline 2-ur college dearee & 0.057 & -0.950 & -2.490 & 0.067 \\
\hline 2-yr college aegree & $(1.103)$ & $(1.208)$ & (8.553) & $(0.094)$ \\
\hline Ambulatory classification & & & & \\
\hline Indenendent & 0.949 & -1.327 & -7.968 & 0.181 \\
\hline inuepenuem & $(1.476)$ & $(1.616)$ & $(11.476)$ & $(0.126)$ \\
\hline Accict device & $4.704^{* *}$ & 1.356 & 20.233 & -0.027 \\
\hline Assist device & $(1.824)$ & (1.998) & (13.838) & $(0.157)$ \\
\hline
\end{tabular}


» CONTINUED FROM PAGE 204

TABLE 6. Postoperative functional outcomes at 3 months: multiple regression

\begin{tabular}{|c|c|c|c|c|}
\hline & \multicolumn{4}{|c|}{ Dependent Variable } \\
\hline & Back Pain & Leg Pain & ODI Score & $E Q-5 D$ \\
\hline \multicolumn{5}{|l|}{ ASA class } \\
\hline \multirow{2}{*}{ II } & 1.514 & 2.659 & 14.356 & $-0.303^{*}$ \\
\hline & (1.891) & $(2.072)$ & $(14.703)$ & $(0.162)$ \\
\hline \multirow{2}{*}{ III } & 1.040 & 2.777 & 15.189 & $-0.384^{* *}$ \\
\hline & (1.971) & (2.163) & (15.341) & $(0.168)$ \\
\hline \multirow{2}{*}{ IV } & -4.822 & 3.959 & -4.570 & -0.248 \\
\hline & $(4.053)$ & $(4.438)$ & $(31.255)$ & $(0.348)$ \\
\hline \multicolumn{5}{|c|}{ Insurance payer } \\
\hline \multirow{2}{*}{ Private } & -1.683 & $-3.518^{* * *}$ & $-16.503^{*}$ & $0.202^{* *}$ \\
\hline & $(1.102)$ & $(1.221)$ & (8.328) & $(0.095)$ \\
\hline \multirow{2}{*}{ VA/gov } & -2.559 & -2.792 & -10.705 & 0.075 \\
\hline & (1.739) & $(1.927)$ & $(12.129)$ & $(0.149)$ \\
\hline \multirow{2}{*}{ Intercept } & 0.513 & 4.949 & 22.308 & $0.540^{*}$ \\
\hline & $(3.615)$ & (3.959) & $(25.860)$ & $(0.310)$ \\
\hline Observations & 69 & 68 & 70 & 70 \\
\hline $\mathrm{R}^{2}$ & 0.434 & 0.473 & 0.454 & 0.496 \\
\hline Adjusted $\mathrm{R}^{2}$ & 0.105 & 0.159 & 0.144 & 0.210 \\
\hline Residual SE & $2.370(\mathrm{df}=43)$ & $2.595(\mathrm{df}=42)$ & $18.443(\mathrm{df}=44)$ & $0.204(\mathrm{df}=44)$ \\
\hline F statistic & $1.319(\mathrm{df}=25 ; 43)$ & $1.506(\mathrm{df}=25 ; 42)$ & $1.464(\mathrm{df}=25 ; 44)$ & $1.734^{*}(\mathrm{df}=25 ; 44)$ \\
\hline
\end{tabular}

Values are presented as parameter estimates (SE) unless noted otherwise.

${ }^{*} p<0.1 ;{ }^{* *} p<0.05 ;{ }^{* * *} p<0.01$.

at 12 months postoperatively, suggesting no age effect on postoperative outcomes. ${ }^{19}$

We performed a multivariate analysis to evaluate the effect of insurance status as an independent predictor of outcomes, considering multiple preoperative characteristics. Depression, BMI $>25$, and lower level of education at baseline were independent predictors of worse back pain at baseline. Positive smoking history and assistance with a wheelchair were associated with worse disability at baseline. Positive smoking history, depression, and wheelchair assistance were associated with worse quality of life. These findings are similar to those of previously reported studies listing depression, BMI, smoking status, education, and ambulation as factors affecting lumbar spinal surgery outcomes. ${ }^{1,5,8,27}$ At 1 year, multivariate analysis indicated that private insurance was associated with improved back pain and improved quality of life (Table 7). Improved back pain and quality of life were again seen when VA-insured patients were excluded from the government insurance cohort (Table 8).

The reason for our reported findings is likely multifactorial. It is known that having Medicare insurance is a paradigm of an older population, given that the requirement for enrollment is age $>65$ years. This population is known to have a higher burden of medical comorbidities, which is reflective of the higher ASA classes identified in our own government insurance cohort. These patients may require more time to recover after invasive surgery or have other health issues and thus report less improvement in their quality of life as a result. ${ }^{22}$ In support of this, Bernatz and Anderson reported that 30-day readmission rates are higher in Medicare and Medicaid populations and in patients in higher ASA classes, which also impacts recovery. ${ }^{6}$ A prolonged nonsurgical course with more advanced disease due to provider practice patterns may also play a role in differences between those with private and those with public forms of insurance.

Patient ownership in their healthcare may be a factor. Conceivably, patients who do not directly pay for their health insurance may have a lesser stake in their own recovery. This has been suggested previously by Chotai et al., who evaluated several factors affecting patient satisfaction after lumbar spinal surgery. ${ }^{8}$ Gazmararian et al. reported that the poor healthcare literacy of Medicare recipients may play a role in their ability to function in the healthcare environment and may affect their ability to be involved in their own care. ${ }^{13}$ Similarly, elderly patients have been reported to benefit less from rehabilitation after surgery; however, this has been studied only in the orthopedic literature on arthroplasty and not in lumbar spinal surgery specifically. ${ }^{26}$

Several studies have examined outcomes in an elderly patient population undergoing lumbar surgery, with varying results. These studies reported that elderly patients do benefit significantly from lumbar spinal surgery, suggesting that advanced age alone should not be a contraindication for surgery. ${ }^{2,12,19,23-25}$ Gautschi et al. reported that older patients undergoing lumbar spinal surgery tended to experience more pain after surgery and reported worse disability and quality of life at last follow-up. ${ }^{12}$ In contrast, 
TABLE 7. One-year functional outcomes: multiple regression

\begin{tabular}{|c|c|c|c|c|}
\hline & \multicolumn{4}{|c|}{ Dependent Variable } \\
\hline & Back Pain & Leg Pain & ODI Score & $E Q-5 D$ \\
\hline \multicolumn{5}{|l|}{ Age, yrs } \\
\hline \multirow{2}{*}{$40-50$} & -1.393 & -0.632 & 2.719 & 0.063 \\
\hline & (3.016) & (2.973) & $(20.369)$ & $(0.209)$ \\
\hline \multirow{2}{*}{$50-60$} & -1.879 & -2.373 & -3.800 & 0.297 \\
\hline & $(3.017)$ & $(2.971)$ & $(19.842)$ & $(0.210)$ \\
\hline \multirow{2}{*}{$60-70$} & -3.421 & -1.045 & -0.781 & 0.220 \\
\hline & (3.281) & $(3.232)$ & $(21.983)$ & $(0.228)$ \\
\hline \multirow{2}{*}{$70-80$} & -4.517 & -2.691 & -6.934 & 0.267 \\
\hline & (3.371) & $(3.346)$ & $(22.550)$ & $(0.234)$ \\
\hline \multirow{2}{*}{ Male sex } & 1.150 & -0.067 & 2.433 & -0.028 \\
\hline & $(1.038)$ & $(1.030)$ & (7.054) & $(0.072)$ \\
\hline \multirow{2}{*}{ Everyday smoker } & 0.069 & -0.196 & 4.041 & -0.043 \\
\hline & $(1.281)$ & $(1.265)$ & $(8.759)$ & $(0.089)$ \\
\hline \multicolumn{5}{|l|}{ Diabetes type 2} \\
\hline \multirow{2}{*}{ Insulin dependent } & -0.516 & 0.064 & 11.004 & -0.073 \\
\hline & (2.061) & $(2.030)$ & $(13.816)$ & $(0.143)$ \\
\hline \multirow{2}{*}{ Non-insulin dependent } & -1.689 & -0.983 & -11.494 & 0.114 \\
\hline & $(1.557)$ & $(1.552)$ & (10.643) & $(0.108)$ \\
\hline \multirow{2}{*}{ Depression disorder } & $2.292^{*}$ & $2.463^{*}$ & 15.191 & -0.091 \\
\hline & $(1.342)$ & $(1.320)$ & $(9.143)$ & $(0.093)$ \\
\hline \multicolumn{5}{|l|}{ BMI } \\
\hline \multirow{2}{*}{$20-25$} & 2.604 & $4.662^{*}$ & 5.114 & 0.066 \\
\hline & (2.403) & $(2.375)$ & $(16.353)$ & $(0.167)$ \\
\hline \multirow{2}{*}{$25-30$} & 0.530 & 3.665 & 6.854 & 0.012 \\
\hline & $(2.257)$ & $(2.225)$ & $(15.415)$ & $(0.157)$ \\
\hline \multirow{2}{*}{$30-35$} & 1.281 & 4.186 & 11.623 & 0.071 \\
\hline & $(2.522)$ & $(2.482)$ & (17.164) & $(0.175)$ \\
\hline \multirow{2}{*}{$\geq 35$} & 0.232 & 4.188 & 10.529 & 0.062 \\
\hline & (2.995) & $(2.971)$ & (19.479) & $(0.208)$ \\
\hline \multicolumn{5}{|l|}{ Level of education } \\
\hline \multirow{2}{*}{ High school or GED } & 0.334 & -0.051 & -3.175 & -0.027 \\
\hline & $(1.066)$ & $(1.073)$ & $(7.286)$ & $(0.074)$ \\
\hline \multirow{2}{*}{ Less than high school } & -3.418 & -4.658 & -16.260 & 0.164 \\
\hline & (3.051) & $(3.004)$ & $(20.848)$ & $(0.212)$ \\
\hline \multirow{2}{*}{ Post-college } & $-2.376^{* *}$ & -1.473 & $-19.647^{\star \star *}$ & $0.172^{\star *}$ \\
\hline & $(1.062)$ & $(1.048)$ & (6.894) & $(0.074)$ \\
\hline \multirow{2}{*}{ 2-yr college degree } & -1.960 & 0.511 & -2.157 & 0.057 \\
\hline & $(1.315)$ & (1.295) & (8.988) & $(0.091)$ \\
\hline Ambulation & & & & \\
\hline Indenondant & -1.842 & -0.273 & -1.709 & -0.062 \\
\hline Independent & $(2.914)$ & $(2.868)$ & (19.911) & $(0.202)$ \\
\hline Whoolchoirhound & $7.115^{\star}$ & $8.698^{* *}$ & 38.342 & $-0.965^{\star \star *}$ \\
\hline Wheelchalr-bound & $(4.164)$ & $(4.105)$ & $(28.474)$ & $(0.289)$ \\
\hline Acsict dovire & 0.314 & 1.939 & 12.185 & -0.198 \\
\hline Assist device & (3.349) & $(3.300)$ & (22.899) & $(0.233)$ \\
\hline ASA class & & & & \\
\hline$\mu$ & -1.810 & -2.620 & 11.023 & 0.137 \\
\hline 11 & $(3.175)$ & $(3.125)$ & $(21.700)$ & $(0.221)$ \\
\hline
\end{tabular}


TABLE 7. One-year functional outcomes: multiple regression

\begin{tabular}{|c|c|c|c|c|}
\hline & \multicolumn{4}{|c|}{ Dependent Variable } \\
\hline & Back Pain & Leg Pain & ODI Score & EQ-5D \\
\hline \multicolumn{5}{|c|}{ ASA class (continued) } \\
\hline \multirow{2}{*}{ III } & -4.467 & -4.388 & 4.628 & 0.249 \\
\hline & (3.190) & (3.139) & $(21.775)$ & $(0.222)$ \\
\hline \multirow{2}{*}{ IV } & -8.597 & -6.057 & -12.226 & 0.298 \\
\hline & (5.314) & (5.231) & $(36.273)$ & $(0.369)$ \\
\hline \multicolumn{5}{|c|}{ Insurance payer } \\
\hline \multirow{2}{*}{ Private } & $-4.326^{* * *}$ & -1.699 & -9.700 & $0.223^{* *}$ \\
\hline & $(1.380)$ & $(1.376)$ & $(9.414)$ & $(0.096)$ \\
\hline \multirow{2}{*}{ VA/gov } & $-3.842^{*}$ & -2.635 & -14.750 & 0.234 \\
\hline & (2.003) & (1.989) & $(13.559)$ & $(0.139)$ \\
\hline \multirow{2}{*}{ Intercept } & $12.253^{*}$ & 5.238 & 15.818 & 0.264 \\
\hline & (6.144) & (6.068) & $(41.222)$ & $(0.427)$ \\
\hline Observations & 58 & 57 & 59 & 58 \\
\hline $\mathrm{R}^{2}$ & 0.588 & 0.514 & 0.483 & 0.616 \\
\hline Adjusted $\mathrm{R}^{2}$ & 0.266 & 0.122 & 0.092 & 0.317 \\
\hline Residual SE & $2.532(\mathrm{df}=32)$ & $2.492(\mathrm{df}=31)$ & $17.315(\mathrm{df}=33)$ & $0.176(\mathrm{df}=32)$ \\
\hline F statistic & $1.826^{*}(\mathrm{df}=25 ; 32)$ & $1.312(\mathrm{df}=25 ; 31)$ & $1.234(\mathrm{df}=25 ; 33)$ & $2.057^{* *}(\mathrm{df}=25 ; 32)$ \\
\hline
\end{tabular}

Values are presented as parameter estimates (SE) unless noted otherwise.

${ }^{*} p<0.1 ;{ }^{* *} p<0.05 ;{ }^{* * *} p<0.01$.

several other studies have identified similar outcomes between younger and older patients after lumbar surgery, suggesting no significant differences in pain improvement or recovery time. ${ }^{2,19,25}$ Further study with larger prospective trials is likely necessary to define the true nature of these outcome differences.

\section{Limitations}

There are several limitations inherent to this study. Only 77 of the total 100 patients had outcomes data at 12 months. We chose to include the 23 patients with outcomes data at 3 months, but not beyond, in the relevant analysis to strengthen the early outcomes data and elucidate the trajectory of patient recovery. These patients were not included in any analyses at 12-month time points. As this study was undertaken as part of a prospective observational registry, data points will be continually completed in the future as the registry is updated. Larger sample sizes and more complete data will be obtained from this prospective registry and will be helpful in further delineating the aforementioned differences. Additionally, the hope for future research is for more participating centers in the QOD, and therefore data that are easily generalizable across states as well as regions of the country.

Another inherent limitation in our analysis is our inability to adjust for patient selection for surgery. It is unclear what, if any, effect this has on our cohort, but it has been documented that rates of lumbar spinal surgery in the Medicare population have been decreasing, ${ }^{7}$ while the rates of surgery in the elderly population in general have been increasing, ${ }^{10}$ which suggests some factor affecting selection for surgery related to this. Medicare reimburse- ment rates may be a factor, as they have been shown to be significantly lower than reimbursement rates for private insurance after lumbar spinal surgery. ${ }^{21}$ It is also possible that some patients in the data set may carry supplemental insurance to their primary carrier, and this may represent a potential confounder. In addition, the combination of those with VA insurance and Medicare may have differences in functional outcomes among them, which should be considered for future study.

This study also has limitations on known patient demographics and characteristics. Although this study has some information on patient comorbidities prior to decompression, it is admittedly somewhat limited in scope. While examination of ASA class did not show significance with respect to patient outcomes, more complete data through the use of a comorbidity index may uncover unforeseen underlying population differences that the present study did not account for. Next, minimally invasive and open surgical approaches were not specifically documented or separated in our database, which could offer significant insight in future study. Lastly, our data set showed a difference in the number of levels decompressed between the 2 populations. In all cases, the number of laminectomies was done according to surgeon and patient indication. However, controlling for factors such as degree of stenosis across patients could strengthen future studies.

\section{Conclusions}

Both private and public insurance patients show marked improvement overall after elective lumbar spinal surgery. Patients with public insurance have slightly less improve- 
TABLE 8. One-year functional outcomes: multiple regression with VA-insured patients excluded

\begin{tabular}{|c|c|c|c|c|}
\hline & \multicolumn{4}{|c|}{ Dependent Variable } \\
\hline & Back Pain & Leg Pain & ODI Score & $E Q-5 D$ \\
\hline \multicolumn{5}{|l|}{ Age, yrs } \\
\hline \multirow{2}{*}{$40-50$} & -1.433 & -0.934 & 0.057 & 0.088 \\
\hline & $(2.967)$ & $(2.786)$ & $(18.000)$ & $(0.195)$ \\
\hline \multirow{2}{*}{$50-60$} & -1.890 & -2.679 & -5.556 & 0.318 \\
\hline & $(2.969)$ & $(2.784)$ & $(17.528)$ & $(0.195)$ \\
\hline \multirow{2}{*}{$60-70$} & -2.958 & -1.568 & -7.923 & 0.295 \\
\hline & (3.248) & $(3.047)$ & $(19.536)$ & $(0.214)$ \\
\hline \multirow{2}{*}{$70-80$} & -3.987 & -3.285 & -15.517 & 0.356 \\
\hline & (3.344) & (3.164) & $(20.085)$ & $(0.220)$ \\
\hline \multirow{2}{*}{ Male sex } & 1.043 & -0.078 & 3.846 & -0.043 \\
\hline & $(1.033)$ & $(0.975)$ & (6.294) & $(0.068)$ \\
\hline \multirow{2}{*}{ Everyday smoker } & 0.706 & 0.236 & 3.814 & -0.029 \\
\hline & $(1.326)$ & $(1.245)$ & (8.137) & $(0.087)$ \\
\hline \multicolumn{5}{|l|}{ Diabetes type 2} \\
\hline \multirow{2}{*}{ Insulin dependent } & -0.993 & -0.532 & 9.057 & -0.071 \\
\hline & (2.064) & $(1.934)$ & $(12.470)$ & $(0.136)$ \\
\hline \multirow{2}{*}{ Non-insulin dependent } & -2.275 & -1.191 & -9.508 & 0.085 \\
\hline & $(1.563)$ & $(1.483)$ & (9.589) & $(0.103)$ \\
\hline \multirow{2}{*}{ Depression disorder } & $2.997^{* *}$ & 1.394 & 3.734 & 0.017 \\
\hline & (1.449) & $(1.358)$ & (8.888) & $(0.095)$ \\
\hline \multicolumn{5}{|l|}{ BMI } \\
\hline \multirow{2}{*}{$20-25$} & 2.782 & 3.412 & -5.841 & 0.162 \\
\hline & (2.423) & $(2.280)$ & $(14.808)$ & $(0.159)$ \\
\hline \multirow{2}{*}{$25-30$} & 0.780 & 2.643 & -1.739 & 0.089 \\
\hline & (2.262) & (2.124) & $(13.874)$ & $(0.149)$ \\
\hline \multirow{2}{*}{$30-35$} & 2.040 & 2.272 & -6.536 & 0.238 \\
\hline & (2.644) & $(2.479)$ & $(16.142)$ & $(0.174)$ \\
\hline \multirow{2}{*}{$\geq 35$} & 0.850 & 2.205 & -7.950 & 0.235 \\
\hline & (3.091) & $(2.914)$ & $(18.038)$ & $(0.203)$ \\
\hline \multicolumn{5}{|l|}{ Level of education } \\
\hline \multirow{2}{*}{ High school or GED } & 0.314 & 0.092 & -0.067 & -0.055 \\
\hline & $(1.115)$ & $(1.079)$ & $(6.844)$ & $(0.073)$ \\
\hline \multirow{2}{*}{ Less than high school } & -3.599 & -3.833 & -8.272 & 0.094 \\
\hline & (3.024) & $(2.835)$ & $(18.559)$ & $(0.199)$ \\
\hline \multirow{2}{*}{ Post-college } & $-2.177^{*}$ & -1.339 & $-19.896^{* * *}$ & $0.181^{* *}$ \\
\hline & $(1.072)$ & $(1.006)$ & (6.219) & $(0.070)$ \\
\hline \multirow{2}{*}{ 2-yr college degree } & -1.161 & 0.241 & -12.989 & 0.164 \\
\hline & $(1.480)$ & $(1.387)$ & $(9.066)$ & $(0.097)$ \\
\hline Ambulation classification & & & & \\
\hline & -1.831 & -0.388 & -2.941 & -0.050 \\
\hline Independent & $(2.879)$ & $(2.700)$ & (17.679) & $(0.189)$ \\
\hline Wheelchair-bound & $8.007^{*}$ & $8.268^{* *}$ & 29.571 & $-0.873^{* * *}$ \\
\hline varieercirali-soura & $(4.128)$ & $(3.874)$ & $(25.356)$ & $(0.272)$ \\
\hline Accict deviro & 1.224 & 3.247 & 17.453 & -0.218 \\
\hline Hosist uevice & (3.524) & $(3.319)$ & $(21.638)$ & $(0.232)$ \\
\hline ASA class & & & & \\
\hline 1 & $9.592^{*}$ & 7.255 & 20.920 & -0.345 \\
\hline 1 & $(5.300)$ & $(4.972)$ & $(32.526)$ & $(0.349)$ \\
\hline
\end{tabular}


TABLE 8. One-year functional outcomes: multiple regression with VA-insured patients excluded

\begin{tabular}{|c|c|c|c|c|}
\hline & \multicolumn{4}{|c|}{ Dependent Variable } \\
\hline & Back Pain & Leg Pain & ODI Score & EQ-5D \\
\hline \multicolumn{5}{|l|}{ ASA class (continued) } \\
\hline \multirow{2}{*}{ II } & $7.847^{*}$ & 4.105 & 23.151 & -0.131 \\
\hline & $(4.085)$ & $(3.842)$ & $(25.006)$ & $(0.269)$ \\
\hline \multirow{2}{*}{ III } & 5.473 & 3.024 & 20.484 & -0.044 \\
\hline & (3.802) & $(3.570)$ & (23.199) & $(0.250)$ \\
\hline \multirow{2}{*}{ Private insurance payer } & $-3.671^{* *}$ & -1.721 & -14.198 & $0.274^{* * *}$ \\
\hline & $(1.402)$ & $(1.333)$ & $(8.584)$ & $(0.092)$ \\
\hline \multirow{2}{*}{ Intercept } & 1.136 & -0.043 & 22.759 & 0.335 \\
\hline & (7.194) & $(6.784)$ & $(43.277)$ & $(0.473)$ \\
\hline Observations & 53 & 52 & 54 & 53 \\
\hline $\mathrm{R}^{2}$ & 0.618 & 0.564 & 0.570 & 0.695 \\
\hline Adjusted $\mathrm{R}^{2}$ & 0.291 & 0.177 & 0.214 & 0.433 \\
\hline Residual SE & $2.489(\mathrm{df}=28)$ & $2.332(\mathrm{df}=27)$ & $15.286(\mathrm{df}=29)$ & $0.164(\mathrm{df}=28)$ \\
\hline F statistic & $1.887^{*}(\mathrm{df}=24 ; 28)$ & $1.457(\mathrm{df}=24 ; 27)$ & $1.601(d f=24 ; 29)$ & $2.653^{* * *}(d f=24 ; 28)$ \\
\hline
\end{tabular}

Values are presented as parameter estimates (SE) unless noted otherwise. ${ }^{*} p<0.1 ;{ }^{* *} p<0.05 ;{ }^{* * *} p<0.01$

ment in quality of life after surgery compared with those with private insurance, but they still benefit significantly from surgical intervention for lumbar spinal stenosis, particularly with respect to functional status.

\section{Acknowledgments}

Dr. Erwood was the North Family Clinical Scholar in the Department of Neurosurgery at the University of Alabama at Birmingham during the study period.

\section{References}

1. Aalto TJ, Malmivaara A, Kovacs F, Herno A, Alen M, Salmi L, et al: Preoperative predictors for postoperative clinical outcome in lumbar spinal stenosis: systematic review. Spine (Phila Pa 1976) 31:E648-E663, 2006

2. Aleem IS, Rampersaud YR: Elderly patients have similar outcomes compared to younger patients after minimally invasive surgery for spinal stenosis. Clin Orthop Relat Res 472:1824-1830, 2014

3. Asher AL, McCormick PC, Selden NR, Ghogawala Z, McGirt MJ: The National Neurosurgery Quality and Outcomes Database and NeuroPoint Alliance: rationale, development, and implementation. Neurosurg Focus 34(1):E2, 2013

4. Asher AL, Speroff T, Dittus RS, Parker SL, Davies JM, Selden N, et al: The National Neurosurgery Quality and Outcomes Database ( $\left.{ }^{2} \mathrm{QOD}\right)$ : a collaborative North American outcomes registry to advance value-based spine care. Spine (Phila Pa 1976) 39 (22 Suppl 1):S106-S116, 2014

5. Athiviraham A, Wali ZA, Yen D: Predictive factors influencing clinical outcome with operative management of lumbar spinal stenosis. Spine J 11:613-617, 2011

6. Bernatz JT, Anderson PA: Thirty-day readmission rates in spine surgery: systematic review and meta-analysis. Neurosurg Focus 39(4):E7, 2015

7. Best MJ, Buller LT, Eismont FJ: National trends in ambulatory surgery for intervertebral disc disorders and spinal stenosis: a 12-year analysis of the national surveys of ambulatory surgery. Spine (Phila Pa 1976) 40:1703-1711, 2015

8. Chotai S, Sivaganesan A, Parker SL, McGirt MJ, Devin CJ: Patient-specific factors associated with dissatisfaction after elective surgery for degenerative spine diseases. Neurosurgery 77:157-163, 2015

9. Copay AG, Glassman SD, Subach BR, Berven S, Schuler TC, Carreon LY: Minimum clinically important difference in lumbar spine surgery patients: a choice of methods using the Oswestry Disability Index, Medical Outcomes Study questionnaire Short Form 36, and pain scales. Spine J 8:968-974, 2008

10. Deyo RA, Mirza SK, Martin BI, Kreuter W, Goodman DC, Jarvik JG: Trends, major medical complications, and charges associated with surgery for lumbar spinal stenosis in older adults. JAMA 303:1259-1265, 2010

11. Elsayed G, Davis MC, Dupépé EC, McClugage SG, Szerlip $\mathrm{P}$, Walters BC, et al: Obese (BMI >30) patients have greater functional improvement and reach equivalent outcomes at 12 months following decompression surgery for symptomatic lumbar stenosis. World Neurosurg 105:884-894, 2017

12. Gautschi OP, Smoll NR, Joswig H, Corniola MV, Schaller K, Hildebrandt $\mathrm{G}$, et al: Influence of age on pain intensity, functional impairment and health-related quality of life before and after surgery for lumbar degenerative disc disease. Clin Neurol Neurosurg 150:33-39, 2016

13. Gazmararian JA, Baker DW, Williams MV, Parker RM, Scott TL, Green DC, et al: Health literacy among Medicare enrollees in a managed care organization. JAMA 281:545-551, 1999

14. Gregebo B, Dai D, Schillberg B, Baehr M, Nyström B, Taube A: Private and non-private disc herniation patients: do they differ? Open Orthop J 8:237-241, 2014

15. Grotle M, Solberg T, Storheim K, Lærum E, Zwart JA: Public and private health service in Norway: a comparison of patient characteristics and surgery criteria for patients with nerve root affections due to discus herniation. Eur Spine J 23:1984-1991, 2014

16. Harris PA, Taylor R, Thielke R, Payne J, Gonzalez N, Conde 
JG: Research electronic data capture (REDCap) - a metadata-driven methodology and workflow process for providing translational research informatics support. J Biomed Inform 42:377-381, 2009

17. Koerner JD, Glaser J, Radcliff K: Which variables are associated with patient-reported outcomes after discectomy? Review of SPORT disc herniation studies. Clin Orthop Relat Res 473:2000-2006, 2015

18. Lad SP, Huang KT, Bagley JH, Hazzard MA, Babu R, Owens TR, et al: Disparities in the outcomes of lumbar spinal stenosis surgery based on insurance status. Spine (Phila Pa 1976) 38:1119-1127, 2013

19. McGirt MJ, Parker SL, Hilibrand A, Mummaneni P, Glassman SD, Devin CJ, et al: Lumbar surgery in the elderly provides significant health benefit in the US health care system: patient-reported outcomes in 4370 patients from the $\mathrm{N}^{2} \mathrm{QOD}$ registry. Neurosurgery 77 (Suppl 4):S125-S135, 2015

20. McGirt MJ, Speroff T, Dittus RS, Harrell FE Jr, Asher AL: The National Neurosurgery Quality and Outcomes Database $\left(\mathrm{N}^{2} \mathrm{QOD}\right)$ : general overview and pilot-year project description. Neurosurg Focus 34(1):E6, 2013

21. Molina CA, Zadnik PL, Gokaslan ZL, Witham TF, Bydon A, Wolinsky JP, et al: A cohort cost analysis of lumbar laminectomy-current trends in surgeon and hospital fees distribution. Spine J 13:1434-1437, 2013

22. Oldridge NB, Yuan Z, Stoll JE, Rimm AR: Lumbar spine surgery and mortality among Medicare beneficiaries, 1986. Am J Public Health 84:1292-1298, 1994

23. Rihn JA, Hilibrand AS, Zhao W, Lurie JD, Vaccaro AR, Albert TJ, et al: Effectiveness of surgery for lumbar stenosis and degenerative spondylolisthesis in the octogenarian population: analysis of the Spine Patient Outcomes Research Trial (SPORT) data. J Bone Joint Surg Am 97:177-185, 2015

24. Shamji MF, Mroz T, Hsu W, Chutkan N: Management of degenerative lumbar spinal stenosis in the elderly. Neurosurgery 77 (Suppl 4):S68-S74, 2015
25. Thornes E, Ikonomou N, Grotle M: Prognosis of surgical treatment for degenerative lumbar spinal stenosis: a prospective cohort study of clinical outcomes and health-related quality of life across gender and age groups. Open Orthop J 5:372-378, 2011

26. Vincent HK, Alfano AP, Lee L, Vincent KR: Sex and age effects on outcomes of total hip arthroplasty after inpatient rehabilitation. Arch Phys Med Rehabil 87:461-467, 2006

27. Weinstein JN, Tosteson TD, Lurie JD, Tosteson ANA, Blood E, Hanscom B, et al: Surgical versus nonsurgical therapy for lumbar spinal stenosis. N Engl J Med 358:794-810, 2008

\section{Disclosures}

The authors report no conflict of interest concerning the materials or methods used in this study or the findings specified in this paper.

\section{Author Contributions}

Conception and design: Elsayed. Acquisition of data: Elsayed. Analysis and interpretation of data: Elsayed, McClugage, Szerlip. Drafting the article: Elsayed, McClugage, Walters. Critically revising the article: Erwood, McClugage, Walters, Hadley. Reviewed submitted version of manuscript: Erwood, McClugage, Davis, Dupépé, Walters, Hadley. Approved the final version of the manuscript on behalf of all authors: Erwood. Statistical analysis: Elsayed, Szerlip. Administrative/technical/material support: Davis, Dupépé, Walters, Hadley. Study supervision: Walters, Hadley.

\section{Correspondence}

Matthew S. Erwood: University of Alabama at Birmingham, AL. merwood@uabmc.edu. 